\title{
TRATAMENTO DE DADOS PESSOAIS E DIREITO TRIBUTÁRIO: A PRIVACIDADE NA PERSPECTIVA FISCALIZAÇÃO DOS DEVERES FUNDAMENTAIS DE PAGAR IMPOSTOS E DE INDIVIDUALIZAÇÃO E IDENTIFICAÇÃO DO INDIVÍDUO
}

\author{
Murillo Cesar de Mello Brandão Filho ${ }^{1}$ \\ Anderson Souza da Silva Lanzillo
}

RESUMO: Nosso estudo faz uma reflexão sobre as garantias fundamentais da intimidade, vida privada e sigilo de dados no contexto do direito tributário brasileiro, adotando como recorte os deveres fundamentais de pagar impostos e de individualização identificação, abordando o sigilo fiscal e o tratamento de dados pessoais necessários ao aperfeiçoamento do Fisco e para efetividade da solidariedade e cidadania fiscal.

PALAVRAS-CHAVE: Proteção de dados. Privacidade. Tributação brasileira. Dever fundamental de pagar impostos. Cidadania fiscal

\section{PROCESSING OF PERSONAL DATA AND TAX LAW: PRIVACY FROM THE PERSPECTIVE INSPECTION OF THE FUNDAMENTAL DUTIES TO PAY TAXES AND INDIVIDUALIZATION AND IDENTIFICATION OF THE PERSON}

\begin{abstract}
Our research aims to analyze the fundamental guarantees of privacy and data confidentiality in the universe of Brazilian tax law, adopting as perspectives the fundamental duty to pay taxes, identification and the processing of personal data necessary for the improvement and effectiveness of solidarity. and fiscal citizenship.

KEYWORDS: Data protection. Privacy. Brazilian tax law. Fundamental duty to pay taxes. Tax Citizenship.
\end{abstract}

\section{INTRODUÇÃO}

A Constituição Federal de 1988 estabeleceu uma série de liberdades, garantias, direitos, programas e políticas públicas para realização dos objetivos fundamentais da República. A concretização de tais previsões depende, por óbvio, do financiamento integral das ações correspondentes e, em um mundo cada vez mais complexo, do tratamento de informações estratégicas.

Os recursos necessários para isso são originados dos próprios cidadãos, conforme a capacidade contributiva de cada um, nos termos preconizados pelo artigo $145, \S 1^{\circ}$, da Carta

\footnotetext{
${ }^{1}$ Mestrando em Direito pelo Programa de Pós-Graduação em Direito da Universidade Federal do Rio Grande do Norte - UFRN. Procurador Federal. Lattes: http://lattes.cnpq.br/4558790742669435 Orcid: http://orcid.org/0000-00025697-8580. E-mail: murillo.brandao.876@ufrn.edu.br

${ }^{2}$ Mestre em Direito e Doutor em Estudos da Linguagem pela UFRN. Professor do Programa de Pós-Graduação em Direito da Universidade Federal do Rio Grande do Norte (UFRN). Lattes: http://lattes.cnpq.br/3248558504481379 Orcid: http://orcid.org/0000-0002-1737-9307 E-mail: adv.andersonss@ gmail.com
} 
Política. Assim, os indivíduos são os responsáveis pelo cumprimento do dever fundamental de pagar impostos - DFPI, situação reconhecida e sedimentada na ordem constitucional brasileira pelo Supremo Tribunal Federal (2016), no julgamento conjunto das ADIs 2.390, 2.386, 2.397 e 2.859, de relatoria do Ministro Dias Toffoli e do Recurso Extraordinário, com repercussão geral reconhecida, $n^{\circ}$ 601.314, de relatoria do Ministro Edson Fachin.

O Fisco é o órgão público encarregado de zelar pelo correto cumprimento DFPI, pela gestão do sistema tributário e pela efetividade da justiça fiscal através da verificação da capacidade contributiva dos cidadãos através da aplicação da norma tributária ao caso concreto por meio do monitoramento das informações relacionadas às possibilidades econômicas dos contribuintes. Para fazer isso, a administração tributária e a advocacia pública fazendária (na inscrição em dívida ativa e cobrança administrativa e judicial) necessitam de instrumentos eficazes a executar suas missões institucionais com denodo. Não existe Estado social sem financiamento. Não há como fiscalizar o recolhimento de impostos sem acesso à informação. A coleta, análise e monitoramento de dados privados de interesse público, com a tutela especial do sigilo e respeito aos direitos individuais dos cidadãos, são os principais meios de concretude arrecadatória e, por corolário, das políticas públicas.

Ocorre que os indivíduos possuem direitos fundamentais, cláusulas pétreas, de proteção de seus dados pessoais e ao livre desenvolvimento da personalidade da pessoa natural (consoante decisão proferida pelo STF na $\left.\mathrm{ADIN} \mathrm{n}^{\circ} 6.387 / \mathrm{DF}\right)$, bem como à intimidade e vida privada (CF, art. $\left.5^{\circ}, \mathrm{X}\right)$ e ao de sigilo de dados (CF, art. $\left.5^{\circ}, \mathrm{XII}\right)$. Harmonizar tais direitos e com aqueles deveres fundamentais é de interpretação extremamente intricada e laboriosa.

O contexto atual de globalização econômica, concentração de capital, de crimes fiscais e, especialmente, o avanço vertiginoso da inovação tecnológica impõe um mundo desafiador, repleto de novas possibilidades e cheio de intensos questionamentos à sociedade brasileira. Essa disrupção impacta severamente os dados pessoais dos cidadãos e, em especial, as garantias fundamentais necessárias ao desenvolvimento da personalidade do indivíduo e, com isso, o próprio futuro sustentável do país. Ao lado desse preocupante cenário, exige-se cada vez mais eficiência e efetividade da atuação do Fisco para incrementar a arrecadação de impostos e ampliar o financiamento estatal. Atualmente, ações estratégicas de inteligência, planejadas com uso intenso de algoritmos e tecnologia e massivos conjuntos de dados, são o cérebro e o coração do combate à sonegação, blindagem patrimonial, fraudes fiscais, lavagem de dinheiro, organizações criminosas e evasão de capital para paraísos fiscais. 
Somada a essa realidade, acrescente-se ainda a eterna crise fiscal do Estado brasileiro (historicamente sempre se gasta muito mais do que se arrecada no Brasil) e os altíssimos índices de inadimplência dos contribuintes. Segundo o relatório "PGFN em números - Exercício 2019, até 31/12/2019 (PGFN, 2020, p. 4)), o montante do estoque de dívida ativa e do Fundo de Garantia por Tempo de Serviço - FGTS sob gestão da Procuradoria-Geral da Fazenda Nacional PGFN era de "R\$2,4 trilhões, envolvendo mais de 19 milhões de débitos sob responsabilidade de 4,9 milhões de devedores.”. O Tribunal de Contas da União, ao analisar a prestação de contas do Presidente da República no exercício de 2019, ratificou o quadro e ressaltou com preocupação os números alarmantes verificados: "Em relação a 2018, o estoque cresceu 11,7\%, enquanto a arrecadação sofreu queda de 1,9\%" (TCU, 2020, p. 292).

Por esses motivos, a conformação entre, de um lado, a proteção de dados e o respeito à intimidade e vida privada (direitos fundamentais) e, de outro, a identificação de informações pessoais e a fiscalização do recolhimento de impostos (deveres fundamentais) é por demais instigante e exige transparência, lucidez e cuidado ao extremo do interprete porque, quanto mais políticas públicas e programas sociais forem escolhidos e pactuados politicamente pela sociedade, maior será o volume do financiamento necessário para tornar essas escolhas uma realidade e, por consequência, mais impostos deverão ser pagos, maior aplicação do direito tributário será preciso, maior atuação do Fisco será exigida e, por tabela, mais informações pessoais precisarão ser tratadas. Do contrário, como decorrência, o significado dessas liberdades civis poderia ser compreendido de forma cada vez mais distante da sua essência originária (proteção do indivíduo contra o arbítrio através da limitação do poder discricionário do Estado).

Trata-se de um ciclo de expansão permanente onde as escolhas democraticamente feitas pela coletividade por mais serviços públicos e por mais coletividade terminam, por desfecho, a impactar cada vez mais a intimidade e a privacidade de cada indivíduo que a integra, tudo em nome do aumento de um pretendido financiamento (impostos e informações) à concretização das políticas públicas na casa comum.

Em face de todas essas perspectivas, nosso estudo reflete sobre a proteção de dados no contexto do direito tributário, utilizando uma perspectiva diferente. Consideramos que o pacto político de constituição do Estado soberano acarreta a assunção pelos cidadãos dos deveres fundamentais de identificação e de pagar impostos. Assim, sopesamos que o compartilhamento compulsório de aspectos da vida privada de interesse público com a administração tributária poderia fazer parte de um dever fundamental de viabilizar a vida social e, como parte integrante 
disso, um dever pessoal de se individualizar do todo coletivo, de se afirmar como pessoa humana (sujeito de direitos da personalidade), de se identificar e prestar informações forçosamente perante os órgãos públicos competentes e de contribuir para a construção permanente da sociedade.

\section{DEVER FUNDAMENTAL DE PAGAR IMPOSTOS}

Os impostos são o preço que os indivíduos pagam por viver em uma sociedade civilizada? Cada escolha importa uma consequência. Cada desafio coletivo assumido impõe um sacrifício comum a ser suportado. A sociedade brasileira firmou em 1988 um acordo político de buscar construir comunitariamente quatro objetivos fundamentais. Eles foram fixados no artigo $3^{\circ}$ da Constituição Federal: 1) Construir uma sociedade livre, justa e solidária; 2) Garantir o desenvolvimento nacional; 3) Erradicar a pobreza e a marginalização e reduzir as desigualdades sociais e regionais; e 4) Promover o bem de todos, sem preconceitos de origem, raça, sexo, cor, idade e quaisquer outras formas de discriminação.

A Constituição é o documento político maior em que a sociedade tutela os direitos individuais (salvaguardas da pessoa humana, acima de tudo, contra o Estado, mas igualmente em face de organizações privadas), bem como materializa os seus anseios e escolhas comuns e estabelece, expressa ou implicitamente, regras, previsões e determinações compulsórias a todos os indivíduos e aos organismos públicos e privados. Não se trata apenas de uma reunião de ideias gerais e abstratas, mas de fixação de normativa máxima com imposições de objetivos, metas e preceitos a serem necessariamente seguidos, concretizados e respeitados (MELLO, 2010). Nessa mesma linha, Heleno Torres (2011, p. 515) entende que as disposições constitucionais "são regras vinculantes de todo o ordenamento para um fim geral ou específicos, que obrigam ao máximo de observância e efetividade e vedam qualquer conduta em sentido contrário ao seu conteúdo teleológico". Sucede que, ao lado de direitos, a Constituição também estabelece deveres fundamentais (salvaguarda da pessoa humana em face de outras pessoas humanas para efetividade e cumprimento dos compromissos e responsabilidades político-comunitários livremente assumidos entre seres humanos). No Estado social, que é justamente o caso do Brasil, sem tributação, fiscalização, arrecadação e a correta aplicação de recursos em programas e políticas públicas não há como existir o Estado democrático de direito.

A lição seminal do Professor José Casalta Nabais (2012, p. 187) ressalta que: “o imposto não pode ser encarado, nem como um mero poder para o estado, nem simplesmente 
como um mero sacrifício para os cidadãos, mas antes como o contributo indispensável a uma vida em comum e próspera de todos os membros da comunidade organizada em estado". Marciano Buffon (2009) destaca, por sua vez, que o princípio fundamental da dignidade da pessoa humana, como condutor de diversos direitos e garantias fundamentais, sociais, culturais e econômicos (especialmente em prol dos menos favorecidos), alça a tributação à condição de dever fundamental dos cidadãos haja vista que o Estado precisa de recursos significativos para assegurar existência digna a todos, o que demanda montante bastante expressivo de impostos a serem pagos. Com esse mesmo entendimento e partindo das mesmas premissas, Meneses e Correta Neto (2016, p. 105) afirmam nessa lógica:

\begin{abstract}
A Constituição Federal de 1988 adota o princípio da dignidade da pessoa humana e como fundamento da República e estabelece como objetivo fundamental a construção de uma sociedade livre, justa e solidária. E a tributação é a principal fonte de recursos para materializar esses objetivos e valores institucionais. Os tributos são necessários, no Estado de Direito, e devem ser repartidos com justiça e isonomia, na proporção da capacidade contributiva de cada cidadão. O princípio da capacidade contributiva, previsto no $\S 1^{\circ}$ do art. 145 , da Constituição Federal de 1988, faculta à Administração Tributária identificar o patrimônio, os rendimentos e as atividades econômicas do contribuinte, desde que respeitados os direitos individuais e os termos da lei, ou seja, a Constituição traz o fundamento da Lei Complementar $n^{\circ}$ 105/2001. [...]
\end{abstract}

O ciclo da cidadania fiscal tem início necessariamente na Constituição ao albergar os deveres fundamentais e, ao mesmo tempo, as garantias fundamentais de que: 1) ninguém será obrigado a fazer ou deixar de fazer alguma coisa senão em virtude de lei (art. $5^{\circ}$, II); 2) o sistema tributário nacional, de arrecadação e distribuição de rendas serão previstos em Lei (artigo 48); 3) o pagamento de impostos, sempre que possível, terá caráter pessoal e será progressivo, conforme a capacidade econômica do contribuinte (artigo $145, \S 1^{\circ}$ ); e 4) somente nos termos de expressa previsão legal e sempre respeitados os direitos individuais, a administração tributária, na busca de efetividade do exercício da sua missão, poderá tratar dados relacionados ao patrimônio, rendimentos e atividades econômicas dos contribuintes (artigo $145, \S^{\circ}$ ).

Optar por viver em um país civilizado faz surgir, de imediato, a consequência do dever fundamental de pagar impostos para ajudar a concretizar esse objetivo conjunto, que tem justificativa total e fundamento pleno na Constituição. Os deveres fundamentais não são considerados antônimos, antíteses ou a face oculta dos direitos individuais. Na verdade, os deveres possuem natureza jurídica-política própria e estão relacionados diretamente com a escolha livre de viver em comunidade de forma ética para realizar o bem comum e o interesse público. 
Com efeito, da mesma forma que os direitos e garantias fundamentais do indivíduo encontram alicerce na Constituição, todos os deveres fundamentais que sustentam as escolhas coletivas realizadas também possuem seus fundamentos maiores na carta política. Em face disso, considerase como principais características dos deveres fundamentais serem reconhecidos por posições jurídicas passivas, autônomas, subjetivas, individuais, universais e essenciais. (NABAIS, 2012).

Prestar informações ao Estado e financiar a vida comum não são meras opções do cidadão ou uma ideia vaga de um compromisso social abstrato no imaginário das pessoas, mas consubstanciam a certeza de que toda escolha livre importa a assunção das consequências lógicas decorrentes, que precisam ser honradas eticamente. Nessa linha, Paul Kirchhof (2020, p. 525) ensina que:

\begin{abstract}
A tributação é a expressão financeira da boa ordem que uma comunidade dá a si mesma. Ela reflete a compreensão do Estado, define as suas tarefas e a esfera de liberdade dos cidadãos. É a base para os deveres mais importantes do povo, modera as diferenças de rendimento e riqueza resultantes das liberdades econômica e concorrenciais, e cria a base para a segurança, a infraestrutura e os serviços sociais garantidos pelo Estado. Os impostos reclamam dinheiro, ou seja, restringem os bens pelos quais as pessoas se esforçam e fazem guerras. A legislação tributária deve, portanto, ser transparente, geral, compreensível e convincente. O direito tributário e a ética fiscal estarão em harmonia se o homem de negócios honesto e o cidadão decente souberem o que é correto ao declararem e pagarem seus tributos.
\end{abstract}

No Brasil, o dever fundamental de pagar impostos foi sedimentado no ordenamento jurídico através do reconhecimento feito pelo Supremo Tribunal Federal (2016), por meio de controle de constitucionalidade concentrado e abstrato, no paradigmático julgamento conjunto das Ações Diretas de Inconstitucionalidade - ADIs nº 2.859 (PTB), 2.390 (PSL), 2.386 (Confederação Nacional do Comércio) e 2.397 (Confederação Nacional da Indústria), de relatoria do Ministro Dias Toffoli e igualmente no julgamento do Recurso Extraordinário, com repercussão geral reconhecida, $\mathrm{n}^{\circ}$ 601.314/SP, em controle de constitucionalidade concreto e difuso, de relatoria do Ministro Edson Fachin.

Nessa decisão conjunta, analisando como tema de fundo a prerrogativa do Fisco de acessar diretamente e sem autorização judicial prévia os dados bancários dos contribuintes, o Pretório Excelso julgou, por maioria de votos, improcedentes os pedidos formulados e consolidou o entendimento de que existem deveres fundamentais implícitos na Constituição Federal que são necessariamente, como consequências essenciais de efetividade de direitos individuais e essenciais para construção da própria sociedade, correlatos aos diversos direitos previstos no texto 
constitucional, haja vista que, principalmente em relação à garantias sociais, não há como estruturar tais direitos sem a correspondente prévia fonte de financiamento. O Ministro Dias Toffoli (STF, 2016, p. 9, 16, 18 e 19-20) fundamentou, nesse julgado, a compreensão de que:

[...] existe confluência entre os deveres do contribuinte (o dever fundamental de pagar tributos) e os deveres do Fisco (o dever de bem tributar e fiscalizar) [...], no Brasil, o pagamento de tributos é um dever fundamental. A propósito do tema, vale destacar, por seu pioneirismo, a obra do jurista português José Casalta Nabais. No livro "O Dever Fundamental de Pagar Impostos", o professor da Faculdade de Direito da Universidade de Coimbra demonstra, em síntese, que, no Estado contemporâneo - o qual é, essencialmente, um Estado Fiscal, entendido como aquele que é financiado majoritariamente pelos impostos pagos por pessoas físicas e jurídicas - pagar imposto é um dever fundamental.

[...] Sendo o pagamento de tributos, no Brasil, um dever fundamental, por representar o contributo de cada cidadão para a manutenção e o desenvolvimento de um Estado que promove direitos fundamentais, é preciso que se adotem mecanismos efetivos de combate à sonegação fiscal.

[...] A sonegação fiscal gera uma série de consequências danosas para a sociedade.A sonegação determina drástica redução da receita pública, o que impacta negativamente na prestação de serviços essenciais pelo Estado e, consequentemente, na concretização de direitos fundamentais sociais, tais como educação, saúde e assistência e previdência sociais.

Com a decisão, o tema $n^{\circ} 225$ foi pacificado e consolidado pelo STF com o entendimento pela inexistência de direito fundamental ao sigilo bancário em face do Fisco, confirmando-se a constitucionalidade da Lei Complementar $\mathrm{n}^{\circ}$ 105/2001 e afirmando-se que referida Lei autoriza a transferência de sigilo e tratamento dos dados aos órgãos da administração tributária, a quem igualmente cabe o dever de conservá-lo criteriosamente. Analisando o conteúdo sob exame, Meneses e Correa Neto (94 e 105) pontuam que:

A Constituição Federal de 1988 adota o princípio da dignidade da pessoa humana e como fundamento da República e estabelece como objetivo fundamental a construção de uma sociedade livre, justa e solidária. E a tributação é a principal fonte de recursos para materializar esses objetivos e valores institucionais.

Os tributos são necessários, no Estado de Direito, e devem ser repartidos com justiça e isonomia, na proporção da capacidade contributiva de cada cidadão. O princípio da capacidade contributiva, previsto no $\S 1^{\circ}$ do art. 145, da Constituição Federal de 1988, faculta à Administração Tributária identificar o patrimônio, os rendimentos e as atividades econômicas do contribuinte, desde que respeitados os direitos individuais e os termos da lei, ou seja, a Constituição traz o fundamento da Lei Complementar $\mathrm{n}^{\circ}$ 105/2001. [...]

[...] para a Administração Tributária, o acesso às informações bancárias é condição necessária para agregar maior justiça ao sistema tributário e assegurar a distribuição correta e transparente dos ônus decorrentes da tributação, sendo a Lei Complementar $\mathrm{n}^{\circ}$ 105/2001 o reconhecimento de meios necessários para que se possa identificar "o patrimônio, os rendimentos e as atividades econômicas do contribuinte, na forma que prevê o artigo $145, \S 1^{\circ}$, da Constituição Federal. 
Viver em sociedade, viabilizar o Estado de Direito e concretizar políticas públicas exigem do cidadão-contribuinte solidariedade e resignação diante da flexibilização criteriosa de parte da sua garantia fundamental à intimidade, vida privada e sigilo de dados em prol da concretização do projeto político-social firmado comunitariamente. Ricardo Lobo Torres (1991, p. 38) reflete nesse ponto que "o tributo é o preço da liberdade". Com isso, a pessoa humana concorda que parte da sua privacidade seja monitorada pelo Fisco em busca da verificação da capacidade contributiva de cada um (Princípio da igualdade tributária), o Estado estrutura seu financiamento através do justo pagamento de impostos e presta serviços, garante direitos e viabiliza políticas públicas determinados e a sociedade estabelece democraticamente os objetivos fundamentais a serem perseguidos por indivíduos e organismos públicos e privados.

\section{SOLIDARIEDADE E O DEVER FUNDAMENTAL DE INDIVIDUALIZAÇÃO E IDENTIFICAÇÃO}

A eleição política de viver em sociedade faz surgir, de imediato, direitos e deveres fundamentais para cada indivíduo para proteção da sua personalidade e, igualmente, para tutela dos seus semelhantes e da vida comum harmônica. A colaboração entre cidadãos, a comunhão de esforços na busca de objetivos fundamentais politicamente pactuados, o respeito mútuo, o reconhecimento e aceitação plena das características, capacidades e limitações pessoais, a confiança recíproca e a boa-fé nas relações revelam atitudes nobres, valores engrandecedores e a essência do fundamental Princípio da solidariedade.

No julgamento pioneiro e referencial encabeçado pela ADI $n^{\circ} 2.859$ e pelo $\operatorname{RE~} n^{\circ}$ 601.314/SP, o Ministro Luís Roberto Barroso (2016, p. 53-54), analisando o vetor da solidariedade, assim se posicionou:

\footnotetext{
O princípio da transparência, significando clareza, abertura e simplicidade, vincula tanto o Estado quanto a sociedade. Se a criação do Estado é um projeto coletivo, deve-se reconhecer que a solidariedade se projeta também no campo fiscal. Assim, o pagamento de tributos é um dever fundamental, lastreado na feição fiscal assumida pelo Estado contemporâneo e no elenco de direitos fundamentais que pressupõem, para sua concretização, o necessário financiamento.
}

Paralelamente aos valores humanos solidários, é preciso ponderar que não é possível conviver com um outro semelhante sem compartilhar minimamente aspectos da individualidade em prol da convivência civilizatória e da construção de um todo comum e plural. A sociedade 
civilmente organizada exige que a pessoa humana entregue um pouco de seu ego em troca de algo superior: a vida comunitária. A República é o lugar onde todos os caminhos individuais se cruzam voluntariamente, os interesses são postos à baila e as diferenças se harmonizam pacificamente por meio da escolha democrática. É exatamente nessa encruzilhada onde o ser individualizado entrega (acredita e investe) parte do seu eu e se transforma em cidadão para construção, a partir daí e ao lado de semelhantes, de um projeto coletivo, comum e solidário.

Nesse verdadeiro caminho da vida e da evolução humana, a opção individual de passar a viver congregado a outros indivíduos faz surgir uma série de reflexões inquietantes: 1) Quanto da personalidade do indivíduo é exclusivo dele e quanto faz parte da sociedade? 2) A espécie Homo Sapiens Sapiens é composta por seres biopsicossociais? 3) Pessoas precisam de outras pessoas para conseguirem desenvolver suas personalidades? 4) A vida comunitária seria possível sem integração entre os seus membros? 5) A sociedade política pode ser considerada como o resultado da união de diversos fragmentos de personalidades dos indivíduos que a integra?

A busca por respostas para essas questões jus-filosóficas talvez esteja presente na espécie humana desde o despertar da sua racionalidade e consciência. No entanto, por mais profunda e ampla que possa ser a interrelação de personalidades de indivíduos na casa comum, o fato é que a pessoa humana permanece constituindo, até os dias atuais, um ser único, complexo, autônomo e titular de direitos individuais essenciais à sua própria dignidade.

Parece existir aqui um desafio complexo e que precisa ser compatibilizado: De um lado, a pessoa humana, célula da sociedade, ser pensante, sujeito de direitos, mas bastante frágil e efêmero, precisando permanentemente de proteção especial da integralidade da sua personalidade para ter uma vida digna e desenvolver-se plenamente. De outro lado, a sociedade, resultado da escolha voluntária e democrática das pessoas humanas de estabelecerem uma vida comunitária, construção política, espaço desafiador de convivência e conformação, que necessita da entrega de partes da personalidade dos seus indivíduos para conseguir se constituir, estruturar, ser livre, justa, solidária e promover o bem de todos.

O dever fundamental de individualização e identificação da pessoa humana recebia pouca atenção da doutrina jurídica até a eclosão da era da tecnologia e do fenômeno da sociedade da informação, que estão gerando intensos debates sobre a proteção de dados pessoais na sociedade da informação. É importante considerar que a existência da pessoa humana precede a ideia de Estado e os próprios princípios fundamentais que alicerçam a República. No entanto, a simples individualização do ser humano pode ser um pressuposto de sua inserção na sociedade 
política e acolhimento pelo ordenamento jurídico. Afinal, sem a fecundação e pelo menos a potencialidade de existência de uma vida humana, não há indivíduo.

Foi com esse entendimento que o Supremo Tribunal Federal, em 2012, julgou a Arguição de Descumprimento de Preceito Fundamental n ${ }^{\circ}$ 54/DF (CNTS), reconhecendo que, à luz da Constituição, não há definição exata sobre o início da vida humana, autorizou a possibilidade de interrupção de gravidez de feto anencefálico (ausência do cérebro ou de partes vitais dele constatada por diagnóstico médico certo). O STF decidiu que não há crime de aborto nesses casos. Ao equiparar o anencéfalo ao natimorto, determinou a aplicação do mesmo regime jurídico para as duas situações e, por consequência, a despenalização da conduta por inexistência de crime (que passou a ser impossível nessas situações). Em seu voto, o Ministro Marco Aurélio afirmou que "O anencéfalo jamais se tornará uma pessoa. Não se cuida de vida em potencial, mas de morte segura." (STF, 2012, p. 46).

Nessa quadra, é forçoso reconhecer que a "personificação" do indivíduo (no sentido de vida ou potencialidade de vida humana) é condição prévia e necessária à aquisição e exercício de direitos da personalidade. Esse é o comando definido pela Lei ${ }^{\circ} 10.406 / 2002$, que institui o Código Civil, ordenando que toda pessoa é capaz de direitos e deveres na ordem civil (art. $1^{\circ}$ ) e que a personalidade civil da pessoa começa do nascimento com vida, resguardando a lei, desde a concepção, os direitos do nascituro (art. $2^{\circ}$ ). A identificação da pessoa humana é um desdobramento lógico da individualização do ser, mas com ela não se confunde, podendo ser conceituada como o dever fundamental de prestar, inserir, fornecer, cadastrar e entregar ao Estado informações relacionadas a uma determinada pessoa natural como instrumento de registro oficial e público, associação personalíssima única e atributo exclusivo desse indivíduo. A identificação, assim, é fonte do dado pessoal, conceituado como informação relacionada a pessoa natural identificada ou identificável pela Lei n ${ }^{\circ}$ 3.709/2018 - LGPD.

A individualização da pessoa humana, a sua identificação perante o Estado e a utilização exclusiva de seus atributos personalíssimos perante todos os outros indivíduos, a sociedade e os organismos públicos e privados são condições fundamentais para o reconhecimento único do ser no universo coletivo social, da particularização da vida, do respeito público às características pessoais, da singularização de direitos e deveres e estabelecimento das bases da confiança mútua nas relações a serem experimentadas. Esses meta-valores estão na essência da vida em sociedade, que necessita de segurança política e jurídica para seu funcionamento regular. Em face desta perspectiva, Lima (2016, p.117) afirma que: 
A identidade humana é fator de segurança jurídica essencial à vida em sociedade. Sua ausência, imprecisão, falsidade ou dissimulação pode repercutir negativamente, notadamente em sede processual penal, quando, exemplificativamente, um inocente pode ser preso em virtude de o verdadeiro autor do delito ter se identificado falsamente. Por conta disso, incumbe ao Estado desenvolver métodos e procedimentos capazes de individualizar e distinguir a pessoa, sem que isso represente violação a direitos fundamentais.

O dever fundamental de identificação pode encontrar fundamento na interpretação sistemática de três previsões constitucionais: 1) O Princípio da Legalidade, que determina que ninguém será obrigado a fazer ou deixar de fazer alguma coisa senão em virtude de lei (BRASIL, 1988, CF, Art. 5, II); 2) A vedação expressa ao anonimato, garantida a livre a manifestação do pensamento (BRASIL, 1988, CF, Art. $5^{\circ}$ ); e, principalmente, 3) A previsão e pressuposição de existência de identificação civil dos indivíduos e, quando essa estiver consolidada, limitando a identificação criminal somente às hipóteses previstas em lei (BRASIL, 1988, CF, Art. 5², LVIII). A materialização desse dever é feita em diversas previsões normativas expressas do ordenamento jurídico brasileiro. Atente-se para algumas:

A Lei $n^{\circ}$ 6.015/1973, que dispõe sobre os registros públicos, determina, em seus artigos 50 e 52, que: 1) todo nascimento que ocorrer no território nacional deverá ser dado a registro, no lugar em que tiver ocorrido o parto ou no lugar da residência dos pais, dentro do prazo de quinze dias, que será ampliado em até três meses para os lugares distantes mais de trinta quilômetros da sede do cartório; 2) o pai e a mãe, isoladamente ou em conjunto, são obrigados a fazer a declaração de nascimento e, no impedimento de ambos, o parente mais próximo, sendo maior achando-se presente. No impedimento deste, a obrigação é transferida, de imediato e sucessivamente, para administradores de hospitais ou os médicos e parteiras, que tiverem assistido o parto. Na ausência desses, para pessoa idônea na casa que o parto ocorrer e, finalmente, para as pessoas encarregadas da guarda do menor.

Os artigos 52 e 53 especificam minuciosamente os dados pessoais que deverão ser coletados compulsoriamente no assento oficial de nascimento. O dever de identificação chega a ser tão profundo, enraizado e avassalador que essa mesma Lei sentencia, nos parágrafos do artigo 52, que, quando o oficial do registro público tiver motivo para duvidar da declaração de nascimento, poderá ir à casa do recém-nascido verificar a sua existência, ou exigir a atestação do médico ou parteira que tiver assistido o parto, ou o testemunho de duas pessoas que não forem os pais e tiverem visto o recém-nascido. Se a dúvida persistir, poderá requerer ao Juiz as providências que forem cabíveis para esclarecimento do fato. 
Atente-se para a Lei ${ }^{\circ}$ 8.069/1990, que dispõe sobre o Estatuto da Criança e do Adolescente, estabelece que hospitais e demais estabelecimentos de atenção à saúde de gestantes, públicos e particulares, são obrigados a identificar o recém-nascido mediante o registro de sua impressão plantar e digital e da impressão digital da mãe. Observe-se, igualmente, a Lei ${ }^{\circ}$ 9.454/1997 que instituiu o número único de registro de identidade civil e o cadastro nacional de registro de identificação civil, destinados a conter os dados de identificação de cada cidadão, criando a centralização de tais informações órgão central do Sistema Nacional de Registro de Identificação Civil. Destaca-se, ainda, a Lei n 9.784/1999, que regula o processo administrativo no âmbito da Administração Pública Federal), dispondo, em seu artigo $4^{\circ}$, que são deveres do administrado perante a Administração expor os fatos conforme a verdade; proceder com lealdade, urbanidade e boa-fé; não agir de modo temerário; prestar as informações que lhe forem solicitadas e colaborar para o esclarecimento dos fatos.

Por seu turno, a Lei n ${ }^{\circ}$ 10.406/2002, que institui o Código Civil, prescreve, no artigo $9^{\circ}$, que serão registrados em registro público: 1) os nascimentos, casamentos e óbitos; 2) a emancipação por outorga dos pais ou por sentença do juiz; 3) a interdição por incapacidade absoluta ou relativa; e 4) a sentença declaratória de ausência e de morte presumida. Veja-se a Lei $\mathrm{n}^{\circ} 12.037 / 2009$ que disciplina a identificação criminal do civilmente identificado, regulamentando o art. $5^{\circ}$, inciso LVIII, da Constituição Federal, bem como a Portaria/Ministério da Saúde ${ }^{\circ}$ 940/2011 regulamenta o Sistema Cartão Nacional de Saúde - Sistema Cartão, asseverando, em seu artigo $2^{\circ}$, que se trata de um sistema de informação de base nacional que permite a identificação unívoca dos usuários das ações e serviços de saúde, com atribuição de um número único válido em todo o território nacional.

Em conclusão, a Lei n ${ }^{\circ}$ 13.444/2017 institui a Identificação Civil Nacional - ICN, com o objetivo de identificar o brasileiro em suas relações com a sociedade e com os órgãos e entidades governamentais e privados, determinando em seu artigo $2^{\circ}$ a utilização de diversas bases de dados para isso. Por sua vez, a Lei ${ }^{\circ} 13.460 / 2017$, que dispõe sobre participação, proteção e defesa dos direitos do usuário dos serviços públicos da administração pública, ordena, em seu artigo $8^{\circ}$, que são deveres do usuário prestar as informações pertinentes ao serviço prestado quando solicitadas. Registra-se, ainda, a Lei $n^{\circ}$ 13.964/2019 que aperfeiçoa a legislação penal e processual penal, criando o banco nacional multibiométrico e de impressões digitais, bem como o Decreto $\mathrm{n}^{\circ}$ 9.723/2019 que fixa o Cadastro de Pessoas Físicas - CPF como instrumento suficiente e substitutivo da apresentação de outros documentos do cidadão no exercício de obrigações e direitos. Por derradeiro, a Lei $n^{\circ} 14.129 / 2021$, que dispõe sobre princípios, regras e instrumentos 
para o Governo Digital e aumento da eficiência da administração pública, especialmente por meio da desburocratização, da inovação, da transformação digital e da participação do cidadão, em seu artigo 28, estabelece que o número de inscrição no Cadastro de Pessoas Físicas (CPF) como número suficiente para identificação do cidadão ou da pessoa jurídica, conforme o caso, nos bancos de dados de serviços públicos, garantida a gratuidade da inscrição e das alterações nesses cadastros.

Como se vê, o dever fundamental de individualização e identificação tem fundamento constitucional, está inserido materialmente no ordenamento jurídico, vem sendo exigido do cidadão brasileiro há muito pelos órgãos públicos e igualmente encontra fundamento doutrinário, conforme Ribeiro (2012, p. 284) se posiciona:

[...] o sujeito passivo e mesmo terceiros de alguma forma relacionados com a obrigação tributária têm o dever de colaborar com a Administração. Em princípio, o legislador tem, portanto, liberdade relativamente ampla para disciplinar e impor tais deveres, do mesmo modo que, em tese, não existe um direito de recusa do contribuinte ao cumprimento do dever.

A simples recusa de se identificar perante o Estado quando este o exigir justificadamente constitui contravenção penal prevista no artigo 68 do Decreto-Lei ${ }^{\circ} 3.688 / 1941$, cujo tipo é o seguinte: "Recusar à autoridade, quando por esta, justificadamente solicitados ou exigidos, dados ou indicações concernentes à própria identidade, estado, profissão, domicílio e residência”. Sobre a penalização da recursa de cumprimento ao dever fundamental de identificação, Nucci (2014, p. 209) explica que:

[...] recusar (negar-se a alguma coisa) à autoridade (funcionário público investido de determinado poder) dados relativos à própria qualificação (elementos individualizadores, como estado civil, profissão, domicílio etc.). A conduta típica volta-se ao poder estatal de exigir do cidadão identificação, vale dizer, saber de quem se trata, para qualquer finalidade.

Em arremate, percebe-se que o dever fundamental de individualização e identificação da pessoa humana possui desdobramentos complexos no direito tributário e constitui a fonte essencial de atuação do Fisco no desempenho de sua missão institucional. Valadão e Arruda (2014, p. 323) são firmes no sentido de que o Estado precisa ter prerrogativas eficazes para fazer o 
tratamento de dados em busca de escorreita atuação funcional e assegurar garantias à sociedade de plena e correta aplicação do direito tributário em face de todos os cidadãos:

\begin{abstract}
Em relação à Administração Tributária, a referida LC visa garantir que o Estado tenha a devida arrecadação, com ferramentas adequadas para desvendar esquemas de sonegação, objetivando que o Estado cumpra seu papel garantidor de direitos e ofereça à população serviços públicos de qualidade. Isto porque a função do Estado fica prejudicada na medida em que alguns contribuintes burlem a Administração Tributária e contribuam menos do que efetivamente deveriam. Os contribuintes que assim se comportam são denominados free riders na linguagem econômica, pois se aproveitam dos bens públicos mantidos pelo Estado, sem, no entanto, contribuírem para eles.
\end{abstract}

A República, pelo exposto, é forjada a partir da lealdade entre cidadãos. Não há inimigos, adversários ou competidores. Os indivíduos devem ser parceiras e responsáveis conjuntamente pela construção da casa comum. Transparência acerca da capacidade econômica do contribuinte, boa-fé e confiança são os valores estruturantes da cidadania fiscal. Na lição de Oliveira (2019, p. 197) "Em busca de um regime republicano substancial, o Estado Democrático de Direito se organiza a partir do princípio da transparência, que se irradia por relações jurídicas complexas, possibilitando tomadas de decisão eficientes, participação social e controle público".

\title{
4. TRATAMENTO DE DADOS PESSOAIS PELO FISCO
}

As informações entregues pelos indivíduos à administração tributária representam uma das principais fontes de dados e condição essencial para a atuação das atividades do Fisco com eficiência. O fundamento maior dessa atuação está no artigo $145, \S 1^{\circ}$ da Constituição que, autoriza, sempre respeitados os direitos individuais e capacidade contributiva, o tratamento de dados com objetivo de identificar patrimônio, rendimentos e atividades econômicas do contribuinte. Nesse sentido, Oliveira (2019, p. 180) afirma que "Os dados fiscais sobre arrecadação e movimentação dos contribuintes tornam-se uma condição de sustentabilidade econômica".

É imperioso erigir um raciocínio lógico-jurídico que permita a concertação das garantias fundamentais da privacidade do indivíduo com o deveres fundamentais de pagar impostos, de individualização e identificação da pessoa humana, bem como a prerrogativa indelegável do Fisco de ter acesso qualificado aos dados pessoais de interesse público para promoção, de forma rigorosamente controlada, do Estado fiscal e, por decorrência, do próprio Estado social. O sigilo 
no tratamento de dados para fins tributários é a segurança máxima da cidadania fiscal e forma eficaz de cumprimento de deveres e de proteção dos direitos fundamentais. Com base nisso, Oliveira (2019, p. 198) argumenta que:

\begin{abstract}
A "quebra” do sigilo fiscal foi desmistificada. Acesso e, não, quebra. Acesso por órgãos com competência funcional para controle de dados, identificação do patrimônio e renda do contribuinte. Informação fiscal. Transparência acerca da capacidade econômica do contribuinte. República é regime que privilegia o espaço público. Mistério, sigilo, informações privilegiadas são circunstâncias excepcionais e merecem todo cuidado e também controle, de forma a se evitar vantagens desmedidas e aumento de poder em desgoverno.
\end{abstract}

A racionalidade, a concretude do princípio da capacidade contributiva e a eficiência de atuação da administração tributária estão diretamente vinculadas à existência, quantidade e qualidade de informações pessoais estruturadas tecnologicamente, como afirma Ichihara (2006, p. 331) "quanto maior a eficiência da fiscalização, maior a efetiva da justiça fiscal”. Na mesma trilha do raciocínio, Valadão e Arruda (2014, p. 339 e 341) argumentam que:

\footnotetext{
O mundo caminha na direção em que o sigilo do ter (em contraposição ao do ser) não possa servir de instrumento protetivo capaz de blindar aqueles que sonegam tributos ou cometem outras formas de ilegalidade.

[...] a troca de informações em matéria tributária constitui um dos núcleos essenciais para detecção de práticas evasivas e elisivas [...]; principalmente nos tempos atuais de economias interpenetradas e interdependentes, onde praticamente todas as organizações empresariais importantes têm operações transnacionais ou são elas mesmas empresas transnacionais

Com a necessidade cada vez maior de ampliar e melhorar os serviços públicos prestados à população, o Estado necessita dar maior efetividade no processo arrecadatório para garantir o cumprimento de sua missão constitucional. Uma fiscalização tributária mais eficaz seria capaz de identificar e cobrar de maneira efetiva os tributos, dissuadindo pessoas físicas e jurídicas de utilizar métodos ilegais como forma de não contribuir com o Estado.
}

Nesse sentido, o big data fiscal é essencial para o aperfeiçoamento da máquina administrativa em busca da almejada cidadania fiscal. A vigilância não pode ser rotulada como controle político ou inquisitoriedade esmagadora de individualidades. Tributação não é dominação e fiscalização não pode ser rotulada de invasão descontrolada da privacidade das pessoas. Em razão do vertiginoso desenvolvimento da vida digital, o tratamento de dados pela administração tributária é essencial para monitoramento eletrônico, ativo, contínuo, dinâmico e permanente do patrimônio, renda e atividade econômica dos contribuintes. Corroborando tal entendimento, Falcão (2011, p. 509) leciona que: 
A vida em sociedade supõe a adesão de um contrato previamente estabelecido. Daí por que o indivíduo não poderia recorrer ao sigilo com o intuito de se furtar ao cumprimento de seu dever cívico de pagar tributos segundo a sua capacidade contributiva. A repartição equânime do fardo tributário é um dever do Estado. Para isso, deve utilizar os meios disponibilizados pelo Estado de Direito [...]

A vigilância fiscal-tributária deve ser rigorosamente controlada para assegurar o cumprimento de deveres fundamentais, preservando integralmente os direitos individuais dos cidadãos de erros e arbítrios que eventualmente possam surgir por parte do Estado. A necessidade de regular processo administrativo ou procedimento fiscal instaurados, bem como a observância dos postulados da finalidade, necessidade e proporcionalidade são vetores nesse caminho. $\mathrm{O}$ monitoramento de dados em tais casos não se trata de um poder absoluto e despótico e está sujeito às mesmas imperiosas limitações constitucionais impostas ao poder de tributar. Com essa percepção, Ribeiro (2012, p. 284) explica que:

[...] os poderes estatais de fiscalizar encontram seus limites nos direitos individuais. Portanto, o poder de fiscalizar não é absoluto, devendo ser ponderado em frente aos direitos fundamentais dos contribuintes, que, por sua vez, também não são absolutos. Ambos, isto é, os direitos e garantias individuais e o poder de fiscal podem entrar, pois, em colisão. Tal conflito deve ser acomodado pela ponderação dos princípios em face da situação fática, de maneira a proporcionar a solução mais razoável e proporcional para o caso em questão.

$\mathrm{O}$ acesso às informações pessoais poderá ser excepcionalmente permitido a agentes públicos tributários, mediante prévia e específica autorização legislativa, caso tais dados sejam essenciais à realização do interesse público, sendo seu tratamento restrito à finalidade institucional do órgão público de lotação do agente autorizado, em ambiente tecnologicamente seguro e com preservação do sigilo subjacente. Existem, assim, quatro condicionantes legitimadoras ao tratamento de dados pessoais feito pelo Fisco: 1) Autorização legislativa, 2) Interesse público na informação, 3) Tratamento vinculado à finalidade do órgão atuante e 4) Preservação do sigilo subjacente.

O sigilo bancário está disciplinado na Lei Complementar $n^{\circ} 105 / 2001$ e o fiscal está regido no artigo 198 do Código Tributário Nacional (alterado pela Lei Complementar $\mathrm{n}^{\circ}$ 104/2001). Com a pacificação do tema $n^{\circ} 225$ pelo Supremo Tribunal Federal, assentou-se que o compartilhamento de dados pelos agentes financeiros do sistema bancário nacional diretamente com o Fisco, sem prévia autorização judicial, constitui uma transferência e não quebra de sigilo, sendo legítimo o tratamento de dados nesses casos por órgãos com competência funcional para 
controle e gestão da informação, identificação do patrimônio, renda e atividade econômica do contribuinte. A transferência de sigilo, nesse sentido, exige atenção aos procedimentos administrativos e cautelas necessárias à conservação dos dados dos contribuintes e está disciplinada pelo Decreto $\mathrm{n}^{\circ} 4.489 / 2002$, que regulamentou o art. $5^{\circ}$ da LC 105/2001 e Decreto ${ }^{\circ}$ $3.724 / 2001$, que tratou do art. $6^{\circ}$ da mesma norma. Como preceitua Oliveira $(2019$, p. 197):

[...] $\mathrm{O}$ atendimento à norma constitucional se dá na esfera da administração tributária quando, diante de informações pessoais do contribuinte, se considere impedida de expôlas ao domínio público, posto se tratar de dados sigilosos. Do contribuinte se exige o dever de cooperação, como decorrência de um imperativo legal e um quadro constitucional, sendo ilegítima a conduta que se esquiva do dever de informar, da mesma forma que se exige essa publicidade das contas do governo. Estamos na Era da Transparência Fiscal, seja do Fisco para com o contribuinte, seja deste perante o Estado e à Sociedade.

Essa solução permite a construção de todo um ecossistema de dados fiscais, que permite inúmeras formas de tratamento de dados por agentes públicos autorizados dentro de uma verdadeira redoma fundamental (o sigilo funciona como uma espécie de escudo das garantias fundamentais), para preservação dos direitos individuais da privacidade dos cidadãos, independente de prévia autorização judicial, viabilizando o cumprimento da eficiente da fiscalização tributária e, por decorrência, da efetividade dos deveres fundamentais de pagar impostos e de individualização e identificação. Por essa razão, Ricardo Lobo Torres (2005, p. 245) considera que:

O dever de transparência incumbe ao Estado, subsidiariamente, e à Sociedade. A sociedade deve agir de tal forma transparente que no seu relacionamento com o Estado desapareça a opacidade dos segredos e da conduta abusiva fundada na prevalência da forma sobre o conteúdo dos negócios jurídicos. O Estado, por seu turno, deve revestir a sua atividade financeira da maior clareza e abertura, tanto na legislação instituidora de impostos, taxas, contribuições e empréstimos como na feitura do orçamento e no controle da sua execução.

O cumprimento do dever fundamental de individualização e identificação constrói a colaboração de todos na ampliação do fluxo de informações entre Estado e cidadão, que é o grande mecanismo ativador da cidadania fiscal. Perfilhando essa compreensão, Assoni Filho (2009, p. 58) diz que 
O trânsito de informações entre Estado e sociedade civil causa uma recíproca aproximação que é ativadora da cidadania. Nesse sentido a transparência e o exercício visível do poder, além de ampliar quantitativamente e qualitativamente a participação cidadã na tomada de decisões políticas, também rompe com o isolamento estatal, uma vez que as estruturas de poder são inseridas na vida cotidiana dos indivíduos.

O tratamento de dados pelo Fisco deve obedecer também ao disposto na Lei $\mathrm{n}^{\circ}$ 13.709/2018 (Lei Geral de Proteção de Dados Pessoais), notadamente em relação à observância do Princípio da finalidade, previsto no artigo $6^{\circ}$, que condiciona a realização do tratamento para propósitos legítimos, específicos, explícitos e informados ao titular do dado (o contribuinte), sem possibilidade de tratamento posterior de forma incompatível com essas finalidades, bem como na adequação às hipóteses específicas de tratamento previstas no artigo $7^{\circ}$, Incisos II (para cumprimento de obrigação legal), III (para execução de políticas públicas) e VI (para o exercício regular de direitos em processo judicial, administrativo ou arbitral). $\mathrm{O}$ mesmo procedimento deve ser considerado em especial para dados sensíveis, na forma fixada no artigo 11 da norma, e, em todos esses casos, respeitando-se os procedimentos previstos no artigo 23 do diploma para tratamento de dados pessoais por pessoas jurídicas de direito público. Desta forma, a LGPD aperfeiçoa a atuação do Fisco no tratamento de dados pessoal, tornando-a um novo e importante vetor de preservação de direitos fundamentais

Por fim, a atuação do Fisco também está sujeita à disciplina da Lei nº 14.129/2021, que dispõe sobre princípios, regras e instrumentos para o Governo Digital, em seu artigo 10, determina que a classificação da informação quanto ao grau de sigilo e a possibilidade de limitação do acesso aos servidores autorizados e aos interessados no processo observarão os termos da Lei de Acesso à Informação e demais normas vigentes. Já no inciso VIII do artigo 24 da citada Lei, há expressa previsão de que os órgãos e as entidades responsáveis pela prestação digital de serviços públicos deverão, no âmbito de suas competências, realizar a gestão das suas políticas públicas com base em dados e em evidências por meio da aplicação de inteligência de dados em plataforma digital.

\section{CONSIDERAÇÕES FINAIS}

A racionalidade entre tratamento de dados pessoais, arrecadação de impostos (Estado fiscal) e gasto público em programas sociais para valorização e desenvolvimento da pessoa humana (Estado social) pode ser o caminho justo para a sociedade alcançar os objetivos 
fundamentais republicanos. Essa é a base dos princípios da boa-fé, transparência e da confiança que devem reger as relações éticas entre cidadãos na busca por objetivos comuns.

O indivíduo é a célula da sociedade, é livre por essência e sua personalidade deve ser tutelada sempre como garantia fundamental, mas não está imune de se responsabilizar pelas consequências das escolhas de um projeto político de viver em comunidade.

A atuação do Fisco rigorosa e efetivamente controlada, analisando estritamente informações privadas de interesse público, realizada em ambiente tecnologicamente seguro e executada por meio de sigilo fiscal é suficiente para tutela das garantias fundamentais da pessoa humana, bem como, ao mesmo tempo, possibilita fiscalização do cumprimento dos deveres fundamentais de pagar impostos e de individualização e identificação dos indivíduos, verdadeiros pressupostos para concretização de direitos sociais, programas e políticas públicas, pactuados comunitariamente no projeto de sociedade politicamente organizada.

A transparência acerca dos direitos e deveres de cada indivíduo, bem como o estabelecimento de limites claros, justificados, razoáveis e proporcionais para o funcionamento da sociedade parece ser uma trilha sustentável da harmonização da vida comum.

\section{REFERÊNCIAS}

ASSONI FILHO, Sérgio. Transparência Fiscal e Democracia. Porto Alegre: Núria Fabris, 2009.

BRASIL. Controladoria-Geral da União - Secretaria de Controle Interno. Prestação de Contas do Presidente da República (PCPR) - Exercício de 2019. - Brasília: CGU, 2020a. Disponível em: https://www.gov.br/cgu/pt-br/assuntos/auditoria-e-fiscalizacao/avaliacao-da-gestao-dosadministradores/prestacao-de-contas-do-presidente-da-republica/arquivos/2019-1/pcpr-2019-livro.pdf. Acesso em: 25 mar. 2021.

BRASIL. Procuradoria-Geral da Fazenda Nacional. PGFN em números: Dados 2019. - Brasília: Secretaria da Receita Federal do Brasil, 2020b. Disponível em: https://www.gov.br/pgfn/pt-br/acesso-ainformacao/institucional/pgfn-em-numeros-2014/pgfn-em-numeros-2020. Acesso em: 25 mar. 2021.

BRASIL. Supremo Tribunal Federal. Arguição de Descumprimento de Preceito Fundamental $\mathbf{n}^{\circ} 54$. Relator Ministro Marco Aurélio, Tribunal Pleno, DJ 30/04/2013. Disponível em: https://redir.stf.jus.br/paginadorpub/paginador.jsp?docTP=TP\&docID=3707334. Acesso em 27 mar 2021.

BRASIL. Supremo Tribunal Federal. Ação Direta de Inconstitucionalidade ${ }^{\circ}$ 2.859. Relator Ministro Dias Toffoli, Tribunal Pleno, DJ 20/10/2016. Disponível em: https://redir.stf.jus.br/paginadorpub/paginador.jsp?docTP=TP\&docID=11899965. Acesso em 17 mar 2021. 
BRASIL. Supremo Tribunal Federal. Recurso Extraordinário n 601.314. Relator Ministro Edson Fachin, Tribunal Pleno, DJ 16/09/2016. Disponível em:

http://redir.stf.jus.br/paginadorpub/paginador.jsp?docTP=TP\&docID=11668355 . Acesso em 17 mar 2021.

BRASIL. Tribunal de Contas da União. Relatório sobre as Contas do Presidente da República (PCPR) Exercício de 2019. Relator Ministro Bruno Dantas - Brasília: TCU, 2020e. Disponível em: https://sites.tcu.gov.br/contas-do-governo/Contas-do-Presidente-da-Republica-2019.pdf . Acesso em: 25 mar. 2021.

BUFFON, Marciano. Tributação e dignidade humana: entre os direitos e deveres fundamentais. Livraria do Advogado. Porto Alegre, 2009.

FALCÃO, Maurim Almeida. O comportamento do contribuinte em face dos Fundamentos Políticos do Tributo e sua postura diante dos Sigilos Bancário e Fiscal. In: SARAIVA FILHO, Oswaldo Othon de Pontes; GUIMARÃES, Vasco Branco (Coords.). Sigilos bancário e fiscal: homenagem ao Jurista José Carlos Moreira Alves. Belo Horizonte: Fórum, 2011.

ICHIHARA, Yoshiaki. Tributação e direitos fundamentais. In: Folmann, Melissa (Coord.). Tributação e direitos fundamentais: propostas de efetividade. Curitiba: Juruá, 2006.

KIRCHHOF, Paul. A ética da justiça fiscal (Tradução Pedro Adamy). Revista Direito Tributário Atual, n. 44, p. 525-544, São Paulo: IBDT, $1^{\circ}$ semestre 2020. Quadrimestral.

LIMA, Renato Brasileiro de. Legislação especial criminal comentada: volume único. 4. ed. Salvador: JusPodivm, 2016.

MELLO, Celso Antônio Bandeira de. Eficácia das normas constitucionais e direitos sociais. São Paulo: Malheiros, 2011.

MENESES, G.C.F.; CORREIA NETO, C.B. Sigilo bancário e fiscal no Brasil: fundamento Constitucional, histórico Legislativo e precedentes judiciais. Prisma Jurídico, São Paulo, v. 15, n. 2 p. 75-109, jul./dez. 2016. DOI: https://doi.org/10.5585/prismaj.v15n2.7045. Disponível em:

https://periodicos.uninove.br/prisma/article/view/7045. Acesso em: 05 mar. 2021.

NABAIS, José Casalta. O dever fundamental de pagar impostos - Contributo para compreensão constitucional do estado fiscal contemporâneo. Coimbra: Livraria Almedina, 2012.

NUCCI, Guilherme de Souza. Leis penais e processuais penais comentadas - vol I. 8. ed. Rio de Janeiro: Forense, 2014.

OLIVEIRA, Daniela Olímpio de. Transparência fiscal, sigilo e a relação republicana fisco e contribuinte. Revista do Instituto de Direito Constitucional e Cidadania - IDCC, Londrina, v. 4, n. 2, p 178-200, dez, 2019. Disponível em: https://www.revistadoidcc.com.br/index.php/revista/article/view/11. Acesso em: 04 mar. 2021. 
RIBEIRO, M. M. A era do controle tributário eletrônico e o direito fundamental à privacidade. Revista de Direitos e Garantias Fundamentais, n. 11, p. 279-300, 2 jun. 2012.

TORRES, Heleno Taveira. Direito Constitucional Tributário e a segurança jurídica: metódica da segurança jurídica do sistema constitucional tributário. São Paulo: Revista dos Tribunais, 2011.

TORRES, Ricardo Lobo. A Ideia de Liberdade no Estado Patrimonial e no Estado Fiscal. Rio de Janeiro: Renovar, 1991.

TORRES, Ricardo Lobo. Tratado de direito constitucional financeiro e tributário: valores e princípios constitucionais tributários. Rio de Janeiro: Renovar, 2005.

VALADÃO, Marcos Aurélio Pereira; ARRUDA, Henrique Porto de. Direitos fundamentais, privacidade, intimidade, sigilos bancário e fiscal, e o consenso internacional. Nomos - Revista do Programa de PósGraduação em Direito - UFC, Fortaleza, v. 34, n. 2, p. 315-344, 2014. Disponível em: http://www.periodicos.ufc.br/nomos/article/view/1226. Acesso em: 6 mar. 2021. 